\title{
The Management of Subcutaneous Emphysema in Pneumothorax: A Literature Review
}

\author{
James Melhorn ${ }^{1}$ (D) Helen E. Davies ${ }^{2}$ \\ Accepted: 15 March 2021 / Published online: 16 April 2021 \\ (C) The Author(s) 2021
}

\begin{abstract}
Purpose of Review Subcutaneous emphysema is often observed by clinicians in the context of pneumothorax. It is usually clinically insignificant, but in a few cases can progress to threaten the patient's vision or airway. A variety of approaches to management of such cases are described in the literature. There no controlled trials and no guidelines on management, other than that the cause should be identified and treated wherever possible. The goal of this article is to review the described approaches to subcutaneous emphysema in pneumothorax and provide a reference to the clinician.

Summary Treatment can be directed primarily towards treating an underlying pneumothorax and / or towards the subcutaneous emphysema. These are not mutually exclusive approaches. Management of the underlying pneumothorax includes conservative management; use of negative suction; siting of wider bore intercostal drains and definitive surgical management. Management of subcutaneous emphysema may include decompression techniques such as: 'blow hole' incisions or subcutaneous angio-catheters or tunnelled drains.

In the current absence of controlled trials is not possible to comment on the efficacy of these techniques: no recommendations on management of subcutaneous emphysema in pneumothorax can be made. Management will be significantly influenced by local technical expertise and patient factors for the foreseeable future.
\end{abstract}

Keywords Subcutaneous emphysema $\cdot$ surgical emphysema $\cdot$ pneumothorax $\cdot$ chest drain suction $\cdot$ intercostal drain $\cdot$ chest drain

\section{Introduction}

Subcutaneous emphysema (SCE) is the finding of air or gas beneath the skin. Clinically, it is recognised as crepitus which has a pathognomonic tactile sensation of "walking in the snow'. Radiographically, it appears as radiolucent striations that traverse the subcutaneous tissues and muscle.

Subcutaneous emphysema is a recognised complication of pneumothorax and is found more commonly in association with pneumothorax than other pathologies $[1,2]$. There are no clear data on the incidence of SCE with pneumothorax but

This article is part of the Topical Collection on Pleural Diseases and Mesothelioma

James Melhorn

james.melhorn@doctors.org.uk

1 Nuffield Department of Clinical Medicine, John Radcliffe Hospital, University of Oxford, Headley Way, Headington OX3 9DU, UK

2 University Hospital Llandough, Penlan Road, Llandough, Penarth CF64 2XX, UK it has been reported in $27 \%$ of trauma and rib fracture patients and in $15-20 \%$ of patients who underwent intercostal drainage treatment of their pneumothoraces [3]. Approximately $7 \%$ of patients develop SCE following medical thoracoscopy [4].

No guidelines on the management of subcutaneous emphysema exist. There are several case-based recommendations in the literature, but no controlled trial has been conducted to date. This article aims to review the techniques described in successful management of SCE.

\section{Methods}

A literature search was performed using PubMed and Google Scholar databases to identify studies published from 1990 to 2020 that contained the terms 'subcutaneous emphysema', 'surgical emphysema' and 'chest drain/tube complication(s)'. We also manually searched the reference lists of studies identified and searched the websites of the British Thoracic Society, European Respiratory Society, Resuscitation Council UK, NICE and Cochrane for specific guidance related to subcutaneous emphysema. 
Articles were excluded if they were not published in English. Our search identified 54 articles. Eight of these were excluded as they related to subcutaneous emphysema in clinical contexts other than pneumothorax.

\section{Aetiology}

Subcutaneous emphysema is thought to arise in spontaneous pneumothorax through the 'Macklin Effect' [5]. The rupture of alveoli in a spontaneous pneumothorax is followed by an air leak into the loose connective tissue surrounding the pulmonary vasculature. This air tracks centripetally along the bronchovascular sheath to the mediastinum. From here, aberrant air is free to follow a continuum of fascial planes that connect the mediastinum and soft tissues. This has been demonstrated in animal studies and can be observed on CT imaging [5].

In traumatic pneumothorax, and in patients treated with an intercostal drain, SCE can result when the parietal pleura is breached. This creates a direct pathway for air into the subcutaneous tissue. In the case of patients with an intercostal drain (ICD) in-situ for whom SCE is evolving, it is hypothesized that the volume of air passing through the parietal pleura from the pleural cavity into subcutaneous tissues exceeds the volume of air being removed from the pleural cavity by the intercostal drain [6]. This could be due to the imbalance in flow rate between a large tear in the parietal pleura and a relatively small bore intercostal drain [7]. Intercostal drain blockage is an example of such an imbalance, and in one series of 25 patients who had subcutaneous emphysema following ICD insertion, drain blockage was the root cause in 6 cases [3].

Subcutaneous emphysema can also arise from migration of the side port of the ICD into the chest wall [3] (suggesting inadequate anchorage) and was responsible for a fifth of cases of SCE in the aforementioned series [3]. Side port migration has been a commonly reported cause in other series [8].

Positive pressure ventilation with the adherent increase in flow rates and pressure across the pleural space into subcutaneous tissues may also result in SCE.

Additionally, subcutaneous emphysema has been reported with bronchopleural fistulae which often result in persistent, refractory pneumothoraces.

Multiple intercostal drain siting similarly heighten the risk of SCE [3].

\section{Morbidity \& Mortality}

In most cases subcutaneous emphysema is self-limiting however; it can be a source of discomfort, dislurement and distress to the patient in the interim.

In a minority of patients SCE can be extensive with tension phenomenon leading to dysphagia, dysphonia, palpebral closure and even airway compromise requiring endotracheal intubation [9].

There are case reports of deaths due to SCE as a result of precipitant ventilatory failure [10-12] while it has been associated with patient deterioration and death by others [13]. It is not possible to estimate mortality rates from SCE given the selective nature of case reports but, it is not insignificant. In their series of patients being treated for pneumothorax with an intercostal drain, Jones et al found an increase in mortality in patients with SCE (16\% versus 5\% in cases where SCE was not present). In the same series it was also noted that SCE was associated with increased length of patient hospital stay (mean 17.5 days versus 11.8 days where SCE was not present) [3].

Subcutaneous emphysema related patient morbidity may be significant with resultant serious adverse sequelae described in the literature including blinding, compartment syndrome, pacemaker malfunction and intracranial hypertension [14] (Fig. 1)

\section{Management Options}

\section{Initial management}

Most SCE is self-limiting and resolves spontaneously without intervention. However, massive subcutaneous emphysemathat extending beyond the torso into the neck and head (1) should be addressed to prevent the complications described above.

Initial management should commence with an assessment of the patient: Any suggestion of impending airway compromise (e.g., progressive dysphonia or, in more advanced cases, stridor) should be addressed first. The patient may require supplemental oxygen: It has been hypothesized that oxygen administration may be of benefit in resorption of air in the case of a continued air leak. The mechanism may be a reduction of the partial pressure of nitrogen in the pleural space relative to oxygen, which is more easily absorbed. [15] Supportive evidence is lacking for this approach however, and it is not part of current guidelines for management of pneumothorax.

The BTS Pleural Diseases Guidelines suggest that management of subcutaneous emphysema should begin with a concerted effort to identify the cause [4]. The most reliable investigation for complications of pneumothorax (including SCE) is thoracic CT. Therefore, in patients without an intercostal drain in-situ who have significant clinical SCE or SCE visible on chest radiograph (SCE can render an underlying intrathoracic cause invisible on plain film) it would be reasonable to obtain a CT thorax as soon as it is safe to do so.

If the patient has SCE in the context of a pneumothorax then the causative pneumothorax should be treated with an intercostal drain if it is possible to do so. In the context of trauma, a larger bore drain $>28 \mathrm{~F}$ has traditionally been 
Fig. 1 a \& b. Axial and coronal slices of a computed tomography scan of thorax demonstrating severe subcutaneous emphysema. This study was from a patient treated at our medical centre who had pneumothorax and pneumomediastinum in the context of metastatic renal cell carcinoma. The arrow denotes metastatic erosion through the chest wall leading to pneumothorax.
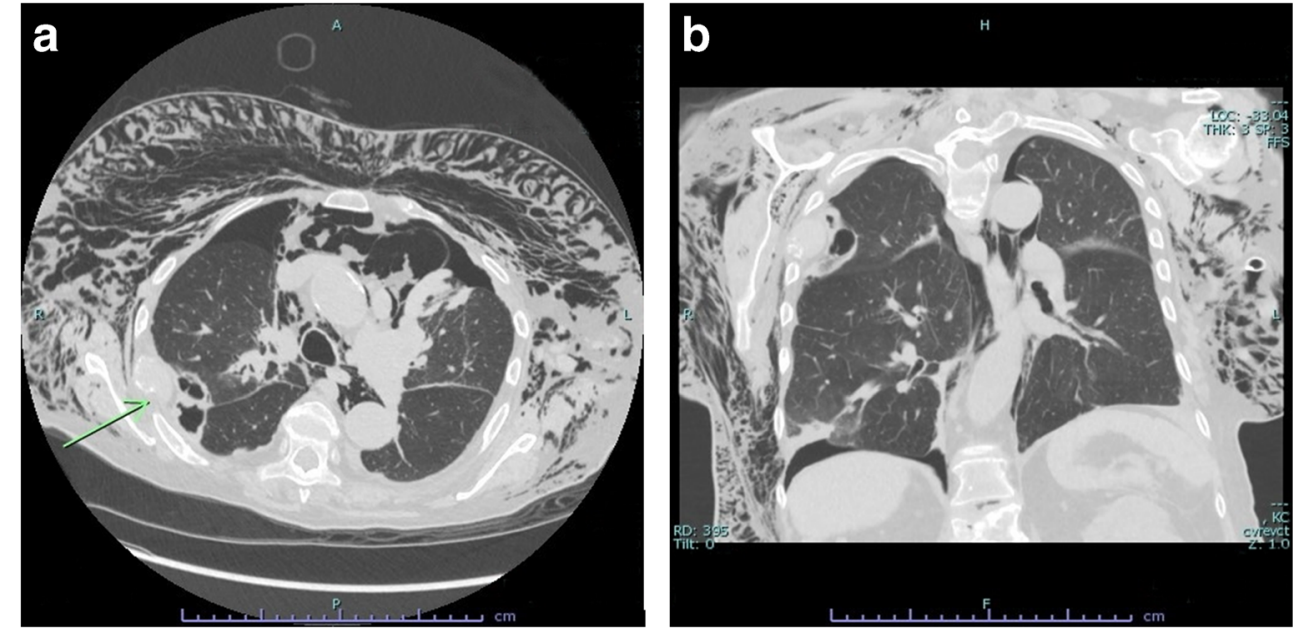

recommended given the potential need for air and/or blood to be evacuated [16] although recent evidence suggests a $14 \mathrm{~F}$ drain is sufficient where there is pneumothorax only; smaller bore drains are better tolerated by patients [17].

In the case of spontaneous pneumothorax the consensus recommendation is for insertion of a smaller bore $(\leq 14 \mathrm{~F})$ intercostal drain $[4,18]$ For patients who already have an intercostal drain in-situ if SCE develops, it is important to ensure that the drain is appropriately placed with all side ports in the thoracic cavity, and that it is neither kinked, blocked or clamped $[8,19]$. If there is doubt about the patency of the ICD this may be assessed by flushing it with a small volume of sterile normal saline.

If the patient has a functioning intercostal drain and the SCE does not resolve or increases, there are a number of options available to the physician. These options are directed at treating either i) the underlying pneumothorax or ii) the subcutaneous emphysema itself. Addressing the subcutaneous emphysema alone may be the only option for physicians looking after patients with SCE from a pneumothorax that cannot be safely drained (e.g., due to its very small size) or if the patient refuses an intercostal drain [20•] or if the end goal of treatment is symptomatic relief only.

The following treatment options are directed primarily at subcutaneous emphysema related to underlying pneumothorax but may be extended to management of SCE arising secondary to pulmonary resection [21] or tracheal or oesophagus perforation $[22,23]$.

\section{Placing an existing intercostal drain on suction}

Traditional one-bottle chest drainage systems and digital thoracic drainage systems allow for the application of negative pressure suction to the pleural cavity. In the case of one-bottle systems this is regulated by the height of a column of water in the suction control chamber. The principle in subcutaneous emphysema, is to increase flow into the chest drain and thereby reduce flow into subcutaneous tissue. There is no consensus on the amount of suction that should be applied to the chest drain in the context of SCE. The degree of suction pressure used in the context of SCE within the literature falls within the range $-0.5 \mathrm{kPa}$ to $-5 \mathrm{kPa}$ ( -5 to $-51 \mathrm{~cm} \mathrm{H}_{2} 0$ ) [21, 24-27]. A survey of leading pleural physicians and thoracic surgical consultants at hospitals in the United Kingdom ${ }^{1}$ found the suction pressures they used in SCE varied across the same range $(-0.5 \mathrm{kPa}$ to $-5 \mathrm{kPa})$ with a median starting pressure of $-2 \mathrm{kPa}$ used.

No comparative studies of the efficacy or safety of differing levels of negative pressure suction for SCE in pneumothorax have been performed. There have been some small randomized trials on the application of suction to chest drains inserted after pulmonary resection. A meta-analysis of these trials in 2010 was unable to draw firm conclusions on the efficacy of suction post-surgically, finding no statistically significant difference in duration of prolonged post-operative air leaks between suction and non-suction patient groups [28].

Harm from application of suction to chest drains is rarely reported in the literature. There is one report of lung segment entrapment and infarction in a chest drain to which very negative suction was applied [29] however, the more commonly occurring complication is patient discomfort and intolerance.

\section{Siting a wider bore intercostal drain}

Some physicians advocate replacing a small-bore drain with a larger bore drain to allow a greater total flow rate of air- this should hypothetically have a potent effect as flow rate is proportional to the fifth power of the radius of the tube (Fanning equation) [7]. A patient with resistant subcutaneous emphysema, despite application of high negative pressure suction, is documented as having improved following siting of a wider bore drain (28F) [30].

In their seven year retrospective cohort study, Cerfolio et al evaluated 255 patients with SCE following elective surgery

\footnotetext{
${ }^{1}$ Unpublished questionnaire data $(\mathrm{n}=21)$
} 
for pulmonary resection. All of these patients were treated with a $28 \mathrm{~F}$ intercostal drain to which $-40 \mathrm{cmH}_{2} 0$ of suction was applied. Some of these patients also had a second intercostal drain sited. Of the latter group, the majority $170(67 \%)$ experienced resolution of their subcutaneous emphysema. It is difficult to know if these results are generalizable to SCE in spontaneous pneumothorax or other causes of pneumothorax, particularly as the SCE experienced by this group was frequently noted to be due to air leaking into the subcutaneous tissues directly from lung that had adhered to the chest wall post-operatively [21].

\section{Draining the subcutaneous emphysema via 'blow holes'}

Subcutaneous emphysema can be decompressed directly through incisions in the skin, so called 'blow holes'. There are multiple reports in the literature of recalcitrant SCE being successfully drained in this manner, with several variations in the technique described. Unilateral and bilateral $[1,31]$ incisions of between 2$4 \mathrm{~cm}$ in length deep to the external thoracic fascia have been used $[1,32]$. These have been placed in both supra-clavicular and infraclavicular positions [32] usually in the midclavicular line. One of the most noteworthy reports of 'blow holes' is the series of 4 ICU patients (3 post thoracic surgery, one patient with ARDS) reported by David Herlan et al in $1992.3 \mathrm{~cm}$ bilateral infraclavicular incisions down to the pectoralis fascia successfully resolved the SCE in all four patients within 2- 4 days. These results are impressive given that each patient from the series had (i) a massive degree of subcutaneous emphysema without obvious pneumothorax (ii) three of the patients were displaying tension phenomenon from the SCE (iii) one patient was undergoing positive pressure ventilation and (iv) re-intubation was avoided in one patient [33•].

Following the 'blow hole' incisions massage is often performed to manually decompress air from the holes - and is reported as significantly accelerating resolution of SCE. In some cases negative pressure wound devices have also been applied on top of the blow hole incisions, operating at pressures of -100 to $-150 \mathrm{mmHg}(-13$ to $-20 \mathrm{kPa})$ with reported good results [34-36]. Disadvantages to the use of blow holes treatment include poor results if an insufficient depth is incised and cosmetic and infection risks [1].

\section{Draining the subcutaneous emphysema via subcutaneous angio-catheters}

Another option is to place fenestrated angio-catheters into the deep and oblique fascial layers of the chest wall. In 2002 Beck et al described the use a fenestrated $14 \mathrm{G}$ venflon placed into the subcutaneous tissue of a patient with SCE under local anaesthetic, $2-3 \mathrm{~cm}$ lateral to the midclavicular line. The fenestrations were made to the catheter over its steel stylette using a scalpel in a spiral pattern (to increase rigidity). The angio-catheter was inserted subcutaneously medially at a $45^{\circ}$ angle so the tip ended approximately 1 to $1.5 \mathrm{~cm}$ deep to the skin before being secured. Multiple variations of this technique have been described regarding, the number of angio-catheters used, positioning of the catheters, and the depth and angle of placement within the subcutaneous tissues [27, 37]. The technique has also incorporated attaching the catheter to an underwater seal as well as compressive massage to enhance drainage $[6,38]$.

In their series of 12 post thoracic surgery patients for whom SCE was treated with angio-catheters and compressive massage 3-4 times per day, Leo et al confirmed successful treatment in $\leq 3$ days for 11 patients. No instances of infection were reported but they did note that the angio-catheters usually became obstructed with clot over time - a finding they noted on removing the angio-catheters [39].

\section{Draining the subcutaneous emphysema via subcutaneous drains}

Rather than draining the subcutaneous space via angiocatheters which, have the potential to kink or block relatively easily, one can use tunnelled subcutaneous drains. The technique for this procedure is described in Tran, Mizumoto \& Mehanna 2018 [24] and O'Reilly, Chen \& Wiseman 2013 [40•]. It involves creation of a subcutaneous tract superficial to the pectoral fascia using blunt dissection into which a prepared (sometimes fenestrated) chest drain is inserted before being secured, connected to a chest drain bottle and underwater seal and (sometimes) placed on low suction.

There are reports of successful use of adapted $12 \mathrm{~F}$ (Seldinger) drains inserted i) unilaterally in the axilla and connected to a drain with $-5 \mathrm{cmH} 20(-0.5 \mathrm{kPa})$ suction [40•] with resolution at 5 days and ii) in the infraclavicular areas bilaterally with application of $-150 \mathrm{mmHg}(-20 \mathrm{kPa})$ suction and manual decompression leading to resolution at 5 days [41]. Wider $26 \mathrm{~F}$ and $28 \mathrm{~F}$ drains have also been tunnelled subcutaneously with reported successful relief of SCE. [24, 30, 42]. There are two case report of patients whose SCE was successfully treated using subcutaneous drains after failure of treatment with wide bore drains on high negative suction [24, 40].

Locally, we have anecdotal experience of the successful use of bilateral tunnelled $12 \mathrm{~F}$ Seldinger drains in one case of massive subcutaneous emphysema unresponsive to an ICD on high negative suction. The time to resolution in our case was 15 hours.

Other types of drains that may be placed subcutaneously include Jackson Pratt and Penrose rubber drains [43]. Cesaria et al describe a series of 20 post parenchymal lung resection patients with massive SCE - of whom 19 had visible pneumothorax - all successfully treated with Penrose type soft rubber drains inserted via supraclavicular micro-incisions $(5 \mathrm{~mm})$ and with repeated massage. Some of these patients had unilateral drains whilst others had bilateral insertions. 
There was a mean time to resolution of 3.7 days. Further variations on this technique can be found in the literature, such as the attachment of a colostomy bag to a subcutaneous drain to keep the site clean and measure air drained [44].

\section{Surgical Options}

Surgery is a potential definitive solution for SCE resulting from a pneumothorax e.g., in the case of bronchopleural fistula however, it is clearly invasive and restricted to those patients who are fit enough for general anaesthesia. This is frequently not the case in patients presenting with spontaneous pneumothoraces secondary to underlying chronic lung disease.

Cerfolio et al [21] followed the progress of 255 patients who had significant post-operative SCE after pulmonary resection. 85 of these cases did not respond to treatment with wide bore intercostal drainage on high negative suction. Of these, 64 patients underwent single incision VATS with pneumolysis and repeat chest tube placement. For 63 of these 64 patients resolution of their SCE was achieved within 24 hours. This group of 64 was observed to have a significantly shorter hospital stay (6 versus 9 days, $p \leq 0.02$ ) than the remaining 21 patients who were not taken back to theatre. However, caution must be taken when interpreting these results as the data are not randomised and inevitable selection bias (for repeat surgery or conservative management) exists. Furthermore, all patients were discharged home with a chest tube attached to a portable device and data pertaining to follow up detail is missing.

Other definitive management strategies for pneumothorax with persistent air leak (+/-subcutaneous emphysema) includes endobronchial valves placement [45] and pleurodeisis [46].

\section{Conclusions}

Most cases of subcutaneous emphysema in pneumothorax are mild and self-limiting and do not require treatment. When SCE develops intercostal drains in-situ should always be checked to make sure they are appropriately placed with all side ports in the thoracic cavity, and that they are neither kinked, blocked or clamped.

Where there is a clinical need to address the subcutaneous emphysema management should be directed towards the cause, if this is possible. Management of the underlying pneumothorax includes conservative management; use of negative suction; siting of wider bore intercostal drains and definitive surgical management. Management of subcutaneous emphysema may include decompression techniques such as: 'blow hole' incisions or subcutaneous angio-catheters or tunnelled drains. These approaches can be used simultaneously.

No definitive recommendations exist to determine the appropriate management of a patient with SCE. In the absence of randomised controlled trials, treatment will continue to be based on case reports and expert opinion. Factors to be considered will include the attending physician's experience and preference, equipment availability, and patient related elements such as clinical (cardiorespiratory) stability, premorbid fitness, patient preference and the response demonstrated to previous pleural procedures.

\section{Declarations}

Human and Animal Rights and Informed Consent This article does not contain any studies with human or animal subjects performed by any of the authors.

Conflict of Interest James Melhorn \& Helen Davies declare no conflict of interest.

Open Access This article is licensed under a Creative Commons Attribution 4.0 International License, which permits use, sharing, adaptation, distribution and reproduction in any medium or format, as long as you give appropriate credit to the original author(s) and the source, provide a link to the Creative Commons licence, and indicate if changes were made. The images or other third party material in this article are included in the article's Creative Commons licence, unless indicated otherwise in a credit line to the material. If material is not included in the article's Creative Commons licence and your intended use is not permitted by statutory regulation or exceeds the permitted use, you will need to obtain permission directly from the copyright holder. To view a copy of this licence, visit http://creativecommons.org/licenses/by/4.0/.

\section{References}

Papers of particular interest, published recently, have been highlighted as:

- Of importance

1. Aghajanzadeh M, Dehnadi A, Ebrahimi H, Karkan MF, Jahromi SK, Maafi AA, et al. Classification and Management of Subcutaneous Emphysema: a 10 Year Experience. Indian J Surg. 2015;77(2):673-7.

2. Abril Molina Ana and Ocete Hita Esther. Subcutaneous Emphysema in Critically Ill Children. SM J Clin Med Imaging. 2018;4(1):1020.

3. Jones P, Hewer RD, Wolfenden HD, Thomas PS. Subcutaneous emphysema asscociated with chest tube drainage. Respirology. 2001;6(2):87-9.

4. Du Rand I, Maskell N. BTS Pleural Disease Guideline. Thorax. 2010;65:ii1-3.

5. Murayama S, Gibo S. Spontaneous pneumomediastinum and Macklin effect: Overview and appearance on computed tomography. World J W J R Radiol. 2014;6(11):850-4.

6. Srinivas R, Agarawal A, Agarawal S. Management of extensive subcutaneous emphysema pneumomediastinum by microdrainage. Time for a rethink? Singap Med J. 2007;48(12):e323.

7. Halifax RJ, Psallidas I, Rahman NM. Chest Drain Size: the Debate Continues. Curr Pulmonol Rep. 2017;6:26-9.

8. Ball CG, Lord J, Laupland KB, Gmora S, Mulloy RH. NA. Chest tube complications: how well are we training our residents? Can J Surg. 2007;50(6):450-8. 
9. Sahoo NK, Singh S, Bhandari A. Early Postoperative Malignant Subcutaneous Emphysema: Report and Review. J Maxillofac Oral Surg. 2017;16(1):85-9.

10. Chea JS, Chae SM, Moon SW. Tension Subcutaenous Emphysema During Laparascopic Surgery Treatment of Colon Cancer: A Case Report. Thorac Cardiovasc Surg. 2014;6:531-4.

11. Conetta R, Barman AA, Iakovou C, Masakayan RJ. Acute ventilatory failure from massive subcutaneous emphysema. Chest. 1993;10:978-80.

12. Saleh Y, Alratroot A. Crepitus and Subcutaneous Emphysema. N Engl J Med. 2020;328(1):e1.

13. Dubin I, Gelber M, Schattner A. Massive Spontaneous Subcutaneous Emphysema. Am J Med. 2016;129(12):e337-8.

14. Kevin Gustavo Alarcón-Meregildo FJP-R, Beato-Pérez JL. Treatment of Severe Subcutaneous Emphysema by Microdrainage. A Case. Rep Arch Bronconeumol. 2014;1:45-9.

15. Macduff A, Arnold A, Harvey J. Management of spontaneous pneumothorax: British Thoracic Society pleural disease guideline 2010. Thorax. 2010;65(Suppl 2):ii18-31.

16. Henry S, Brasel K, Stewart RM. Advanced Trauma Life Support. 10th ed. American College of Surgeons; 2018.

17. Kulvatunyou N, Erickson L, Vijayayasekaran A, Gries L, Joseph B, Friese RF. Randomized clinical trial of pigtail catheter versus chest tube in injured patients with uncomplicated traumatic pneumothorax. Br J Surg. 2014;101:17-22.

18. Baumann MH, Group APC, Al E. Management of spontaneous pneumothorax: an American college of chest physicians Delphi consensus statement. Chest. 2001;119:590-602.

19. Jones PM, Hewer RD. D WH, Thomas P S. Subcutaneous Empysema Associated with Chest Tube Drainage. Respirology. 2001;6(2):87-9.

20• Beck PL, Heitman SJMC. Simple construction of a subcutaneous catheter for treatment of severe subcutaneous emphysema. Chest. 2002;121:503-5 This article describes the technique of insertion of a fenestrated angiocatheter into the chest wall for relief of subcutaneous emphysema.

21. Cerfolio RJ, Bryant AS. MLM. Management of subcutaneous emphysema after pulmonary resection. Ann Thorac Surg. 2008;85(5): 1759-65.

22. Boongsarungsuk V, Suwatanapongched T, Korrungruarg P, Raweelert P. A patient with Subcutaneous Emphysema following endoctracheal intubation. Respir Care. 2012;57(7):1191-4.

23. Glare SC. and P. Subcutaneous Emphysema In Advanced Cancer. J Pain Symptom Manag. 2000;19(1):73-7.

24. Tran Q. Mizumoto R\& MD. Management of extensive surgical emphysema with subcutaneous drain: A case report. Int J Surg Case Rep. 2018:44:126-30.

25. Ringvold $\mathrm{CHO}$, Weinreich UM. A case report of tardive subcutaenous emphysema in relation to iatrogenic pneumothorax. SAGE Open Med Case Rep. 2019;7:1-3.

26. Paramasivam E, Bodenham A. Air leaks, pneumothorax and chest drains. Contin Educ Anaesthesia, Crit Care Pain. 2008;8(6):204-9.

27. Brenton R. Rapid resolution of severe subcutaneous emphysema with simple percutaneous angiocatheter decompression. J Surg Case Rep. 2018;7:1-13.

28. Deng B, Tan Q-Y, Zhao Y-P, Ru-Wen Wang Y-GJ. Suction or nonsuction to the underwater seal drains following pulmonary operation: meta-analysis of randomized controlled trials. Eur J Cardiothorac Surg. 2010;38(2):210-5.

29. Kwiatt M, Tarbox A, Seamon MJ, Swaroop M, Cipolla J, Allen C, et al. Thoracostomy tubes: A comprehensive review of complications and related topics. Int J Crit Illn Inj Sci. 2014;4(2):143-55.

30. C KM. Relief of tension subcutaneous emphysema using a large bore subcutaneous drain. Anaesthesia. 1995;50:1077-9.
31. Dumont SW, Farag A. Life threatening subcutaneous emphysema. Anaesthesia. 2008;63:202-13.

32. Turnbull DK, Heap MJ. Subcutaneous Emphysema and Respiratory Failure Managed with Infraclavicular Blow Holes. Acta Anaesthesiol Scand. 2002;46(2):227.

33. Herlan DB, Landreneau RJ, Ferson PF. Massive Spontaenous Subcutaenous Emphysema: Acute Management with Infraclavicular "Blow Holes". Chest. 1992;102:503-5 This article describes the technique of making 'blow hole' incisions in the chest wall for relief of subcutaneous emphysema.

34. Byun CS, Choi JH, Hwang JJ, Kim DH, Cho HM. SJP. Vacuumassisted closure therapy as an alternative treatment of subcutaneous emphysema. Korean J Thorac Cardiovasc Surg. 2013;46(5):383-7.

35. Sciortino CM, Mundinger GS, Kuwayama DP, Yang SC, Sussman MS. Case Report: Treatment fo Severe Subcutaenous Emphysema With a Negative Pressure Wound Therapy Dressing. Open Access J Plast Surg. 2009;9:1-7.

36. Son BS, Lee S, Cho WH, Hwang JJ, Kim KD, Kim DH. Modified blowhole skin incision using negative pressure wound therapy in the treatment of ventilator-related severe subcutaneous emphysema. Interact Cardiovasc Thoraic Surg. 2014;19:904-7.

37. Madan K, Mehta S, Gupta N, Hadda V, Mohan A, Guleria R. Pneumomediastinum and Extensive Subcutaneous Emphysema after Cryoprobe Transbronchial Lung Biopsy. AnnalsATS. 2016;13(11):2101-3.

38. Alarcón-Meregildo KG, Polo-Romero FJ, Beato-Pérez JL. Treatment of severe subcutaneous emphysema by microdrainage. A case report. Arch Bronconeumol. 2014;50(1):45-9.

39. Leo F, Solli P, Veronesi G, Al E. Efficacy of microdrainage in severe subcutaneous emphysema. Chest. 2002;122:1498-9.

40• O'Reilly P, Chen HK, Wiseman R. Management of extensive subcutaneous emphysema with a subcutaneous drain. Respirol Case Rep. 2013;1(2):28-30 This article describes the technique of subcutaneous drain insertion in the chest wall for relief of subcutaneous emphysema.

41. Ahmed Z, Patel P, Singh S, Sharma RG, Somani PGA, Al E. High negative pressure subcutaneous suction drain for managing debilitating subcutaneous emphysema secondary to tube thoracostomy for an iatrogenic post computed tomography guided transthoracic needle biopsy pneumothorax: case report and review of literat. Int J Surg Case Rep. 2016;26:138-41.

42. Johnson CHN, Lang SA, Bilal H, Rammohan KS. In patients with extensive subcutaneous emphysema, which technique achieves maximal clinical resolution: infraclavicular incisions, subcutaneous drain insertion or suction on in situ chest drain? Interact Cardiovasc Thorac Surg. 2014;18:825-9.

43. Cesario A, Margaritora S, Porziella V, Granone P. Microdrainage via Open Technique in Severe Subcutaneous Emphysema. Chest. 2003;123:2161-2.

44. Matsushita T, Huynh AT, Taranpreet S, Thomson D. Management of Life-Threatening Subcutaneous Emphysema Using Subcutaneous Penrose Drains and Colostomy Bags. Hear Lung Circ. 2007;16(6):469-71.

45. Abu-Hijleh M, Blundin M. Emergency Use of an Endobronchial One-Way Valve in the Management of Severe Air Leak and Massive Subcutaneous Emphysema. Lung. 2010;188:253-7.

46. How C-H, Hsu H-H, Shin-Cheng J. Chemical pleurodeisis for spontaneous pneumothorax. J Formosa Med Assoc. 2013;112(12):749-55.

Publisher's Note Springer Nature remains neutral with regard to jurisdictional claims in published maps and institutional affiliations. 